\title{
NT-proBNP and the Risk of Dementia: A Prospective Cohort Study with 14 Years of Follow-Up
}

\author{
Juho Tynkkynen $^{\mathrm{a}, *}$, Tiina Laatikainen ${ }^{\mathrm{b}, \mathrm{c}, \mathrm{d}}$, Veikko Salomaa ${ }^{\mathrm{b}}$, Aki S. Havulinna ${ }^{\mathrm{b}}$, Stefan Blankenberg ${ }^{\mathrm{e}, \mathrm{f}}$, \\ Tanja Zeller ${ }^{\mathrm{e}, \mathrm{f}}$ and Jussi A. Hernesniemi ${ }^{\mathrm{a}}$

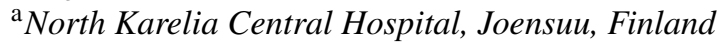 \\ ${ }^{\mathrm{b}}$ National Institute for Health and Welfare, Helsinki, Finland \\ ${ }^{\mathrm{c}}$ Institute of Public Health and Clinical Nutrition, University of Eastern Finland, Kuopio, Finland \\ ${ }^{\mathrm{d}}$ Hospital District of North Karelia, Joensuu, Finland \\ ${ }^{\mathrm{e}}$ German Center for Cardiovascular Research (DZHK), Partner Site Hamburg/Lübeck/Kiel \\ ${ }^{\mathrm{f}}$ University Heart Center Hamburg, Department of General and Interventional Cardiology, Germany
}

\begin{abstract}
.
Background: Memory disorders and Alzheimer's disease (AD) share the same risk factors with cardiovascular diseases. Objective: We tested whether elevated N-terminal pro-brain natriuretic peptide (NT-proBNP) levels would predict any incident dementia or AD.

Methods: The association between NT-proBNP and the risk of dementia was evaluated in a total of 7,158 subjects without previous memory disorders in a prospective study with a median follow-up of 13.8 years.

Results: A total of 220 new dementia cases occurred, of which 149 were AD. Baseline logNT-proBNP levels were associated significantly with the risk of dementia in the entire study population (HR 1.32, 95\% CI 1.17-1.56, $p=0.001$ ) per 1SD difference, adjusted for multiple cardiovascular risk factors. Integrated discrimination improvement (IDI) and continuous net-reclassification improvement (continuous NRI) were improved in the study population over 40 years of age: continuous NRI was $17.5 \%$ (95\% CI 4.4-30.6\%, $p=0.009$ ) and IDI was 0.005 (95\%CI 0.001-0.010, $p=0.021)$. Regarding AD, the HR for 1SD logNT-proBNP change was $1.23(95 \% \mathrm{CI} 1.01-1.49, p=0.040)$ in the entire study population, but no IDI or continuous NRI improvement was seen.

Conclusion: NT-proBNP is also an independent risk marker for dementia, and patient discrimination regarding dementia risk could be improved by using it.
\end{abstract}

Keywords: Alzheimer's disease, biological marker, dementia, N-terminal pro-BNP, population-based, prospective studies, risk

\section{INTRODUCTION}

In recent years, more interest has been focused on the role of cardiovascular risk factors in risk of future dementia. Prospective studies have shown that traditional cardiovascular disease risk factors such as

\footnotetext{
*Correspondence to: Juho Tynkkynen, Pohjois-Karjalan Keskussairaala, Tikkamäentie 16, 80210 Joensuu, Finland. Tel.: +35 850 521 9391; Fax: +35 813171 3229; E-mail: juho.tynkkynen@ gmail.com.
}

diabetes and high blood glucose [1,2], high blood pressure [3, 4], smoking [5, 6], and hypercholesterolemia [7] are also risk factors for dementia. Some of these risk factors seem to interact with APOE status, modifying the dementia risk $[8,9]$. With these easily available parameters, it is possible to predict future dementia risk to a certain degree by using risk scores developed for dementia (CAIDE) or even for cardiovascular risk assessment (Framingham Risk Score - FRS) [10-12].

Currently, new biomarkers like brain natriuretic peptide (BNP) or N-terminal pro-brain natriuretic 
peptide (NT-proBNP) are emerging in cardiovascular risk prediction. Increased NT-proBNP level seems to predict cardiovascular events [13], but also specifically ischemic strokes $[14,15]$ and atrial fibrillation $[16$, 17]. In clinical practice, NT-proBNP is used to diagnose and screen for congestive heart failure [18]: to exclude chronic heart failure, the level of $125 \mathrm{pg} / \mathrm{mL}$ is an optimum cut-off point, according to the European Heart Association recommendation and, to exclude acute heart failure the $300 \mathrm{pg} / \mathrm{mL}$ cut-off point can be used together with clinical assessment in an emergency setting [19]. No clinical guidelines exist for using NTproBNP in any cardiovascular disease risk prediction. In the general population, NT-proBNP is associated with cardiovascular death, non-fatal myocardial infarction, or non-fatal stroke [20], and all of these cardiovascular diseases are associated with cognitive impairment and dementia $[1,21]$.

Few studies have examined the connection between BNP or NT-proBNP and dementia itself. These studies have shown elevated brain natriuretic peptide levels (BNP or NT-proBNP) in peripheral blood to be associated with cognitive dysfunction in patients with cardiovascular disease [22, 23], with the conversion of mild cognitive impairment to dementia [24] and with more decreased cognitive function in demented patients [25]. To the best of our knowledge, two prospective population-based studies have evaluated the association of increased NT-proBNP level with the risk of dementia. The first study included participants over 75 years of age, and the second was conducted among patients with type 2 diabetes aged 60-75. In both studies, a higher NT-proBNP or BNP level was associated with a higher risk of dementia in the followup [26, 27]. Furthermore, a correlation between plasma BNP levels to cerebrospinal fluid levels of amyloid- $\beta$ and tau was observed in patients with mild cognitive impairment or Alzheimer's disease (AD) [28].

The aim of this study was to assess in a prospective population-based study whether an increased NTproBNP level before the age of 75 is associated with the risk of future dementia, regardless of other cardiovascular risk factors and comorbidities.

\section{MATERIALS AND METHODS}

\section{Subjects and follow-up}

The National FINRISK 1997 Study is a national population-based health examination survey conducted in five geographic areas of Finland including people aged 25 to 74 . The original random popula- tion sample was stratified by area, gender, and 10-year age group according to the World Health Organization (WHO) MONICA (MONItoring trends and determinants of CArdiovascular disease) protocol [29, 30]. In total, 8,446 subjects were included in this survey (50.4\% men). All the participants gave their written informed consent, and the survey was conducted in accordance with the Declaration of Helsinki. Ethics approval was received from the Ethics Committee of the National Public Health Institute. The study protocol consisted of a baseline questionnaire and baseline measurements made by specially trained research nurses using the standardized WHO MONICA protocol [31], which is described in more detail in the Supplementary Material. The follow-up was performed using data from the Finnish Hospital Discharge Register, the Causes of Death Register, and the National Social Insurance Institution's Drug Reimbursement Register, with good diagnostic specificity for dementia but having lower sensitivity [32]. The exact follow-up protocol and dementia and other disease definitions are described in the Supplementary Material and Supplementary Table 1.

\section{Statistics}

Excluded from the analysis were participants with prevalent dementia or a degenerative disease affecting the central nervous system $(n=16)$, any kind of stroke or subarachnoidal hemorrhage (an additional 128 subjects), congestive heart failure (an additional 190 subjects), a calculated glomerular filtration rate of $<30$ (Cockcroft-Gault) or missing creatinine at baseline (an additional 567 subjects), or subjects with any other missing data (an additional 387). The final sample comprised 7,158 participants. We used Student's t-test and $\chi^{2}$-test to evaluate the differences between subjects with and without incident dementia in follow-up. To evaluate the association of NT-proBNP with future dementia, we used Cox regression with a forward selection algorithm using the $p$-value 0.1 for inclusion in the model for adjusting variables. Adjusting variables were selected from among age, gender, years of education, and other cardiovascular risk factors and are listed in Table 1. More detailed statistical procedures are presented in the Supplementary Material.

\section{Assays}

After the baseline measurements described in the Supplementary Material, a venous blood specimen was 
Table 1

Baseline characteristics of the total study group divided by incident dementia

\begin{tabular}{|c|c|c|c|c|}
\hline & Total population & $\begin{array}{c}\text { Remained free } \\
\text { of dementia }\end{array}$ & Incident dementia & $\begin{array}{c}p \text {-value by } t \text {-test } \\
\text { or } \chi^{2} \text {-test* }\end{array}$ \\
\hline $\mathrm{n}$ & 7158 & 6938 & 220 & \\
\hline Age, mean (SD), Y & $48.1(13.1)$ & $47.4(12.9)$ & $66.2(6.0)$ & $<0.001$ \\
\hline Gender, M (\%) & $3562(49.8)$ & 3449 (49.7) & $113(51.4)$ & 0.629 \\
\hline Total cholesterol, mean (SD), mg/dL & $213.9(40.5)$ & $213.5(40.9)$ & $223.9(36.7)$ & $<0.001$ \\
\hline High density lipoprotein, mean (SD), mg/dL & $54.1(13.9)$ & $54.1(13.9)$ & $52.1(13.9)$ & 0.038 \\
\hline Triglyceride, mean (SD), mg/dL & $57.1(37.8)$ & $57.1(37.8)$ & $63.7(35.9)$ & 0.006 \\
\hline Creatinine, mean (SD), mg/dL & $0.91(0.25)$ & $0.91(0.25)$ & $0.92(0.16)$ & 0.468 \\
\hline Systolic blood pressure, mean (SD), mmHg & $136(19.6)$ & $135(19.4)$ & $149(20.1)$ & $<0.001$ \\
\hline Diastolic blood pressure, mean (SD), $\mathrm{mmHg}$ & $82.2(11.2)$ & $82.1(11.2)$ & $83.6(11.1)$ & 0.060 \\
\hline Body mass index, mean (SD), $\mathrm{kg} / \mathrm{m}^{2}$ & $26.6(4.5)$ & $26.6(4.5)$ & $27.0(3.8)$ & 0.132 \\
\hline Current smoker $(\%)$ & $1692(23.6)$ & 1659 (23.9) & $33(15)$ & 0.002 \\
\hline Education years, mean (SD), Y & $11.4(3.9)$ & $11.5(3.9)$ & $8.82(3.9)$ & $<0.001$ \\
\hline Prevalent diabetes $(\%)$ & $388(5.4)$ & $357(5.1)$ & $31(14.1)$ & $<0.001$ \\
\hline Prevalent atrial fibrillation (\%) & $74(1.0)$ & $68(1.0)$ & $6(2.7)$ & 0.012 \\
\hline Prevalent ischemic heart disease (\%) & $349(4.9)$ & $322(4.6)$ & $27(12.3)$ & $<0.001$ \\
\hline Cholesterol lowering medication (\%) & $226(3.2)$ & $208(3.0)$ & $18(8.2)$ & $<0.001$ \\
\hline Antihypertensive medication (\%) & $866(12.1)$ & $810(11.7)$ & $56(25.5)$ & $<0.001$ \\
\hline Binge drinking $(\%)$ & $444(6.2)$ & $437(6.3)$ & $7(3.2)$ & 0.064 \\
\hline NT-proBNP, mean (SD), pg/mL & $72.2(150.3)$ & $69.5(147.1)$ & $156.4(212.4)$ & $<0.001$ \\
\hline
\end{tabular}

${ }^{*} p$-value for difference between the subjects remained free of dementia and subjects with incident dementia.

taken and stored at $-70^{\circ} \mathrm{C}$. Lipid testing was carried out in the central laboratory of the National Institute for Health and Welfare (formerly the National Public Health Institute) in Helsinki, with external quality control by the World Health Organization Regional Lipid Reference Center in Prague. The NT-proBNP was determined from serum samples by the electrochemiluminescence sandwich immunoassay ECLIA (Roche Diagnostics, Elecsys 2010), and the intra-assay coefficient of variation was $2.11 \%$ [13]. NT-proBNP levels below the detection level $(5 \mathrm{pg} / \mathrm{mL})$ were handled as $5 \mathrm{pg} / \mathrm{mL}$. NT-proBNP was measured in the MORGAM Mainz Biomarker Laboratory.

\section{RESULTS}

Median follow-up time was 13.8 years, with an accumulated follow-up time of 94,600 person-years. A total of $220(3.1 \%)$ new cases of dementia and 684 $(9.7 \%)$ deaths due to any cause were recorded during the follow-up. Baseline characteristics and univariate associations between putative risk factors and incident dementia are presented in Table 1. Briefly, baseline NT-proBNP levels, as well as many other traditional risk factors, were associated significantly with incident dementia in univariate models.

Distribution of NT-proBNP at baseline among subjects with and without incident dementia is presented in Fig. 1. In total, 452 subjects ( $83 \%$ men) had NTproBNP under the detection level of $5 \mathrm{pg} / \mathrm{mL}$. Of all

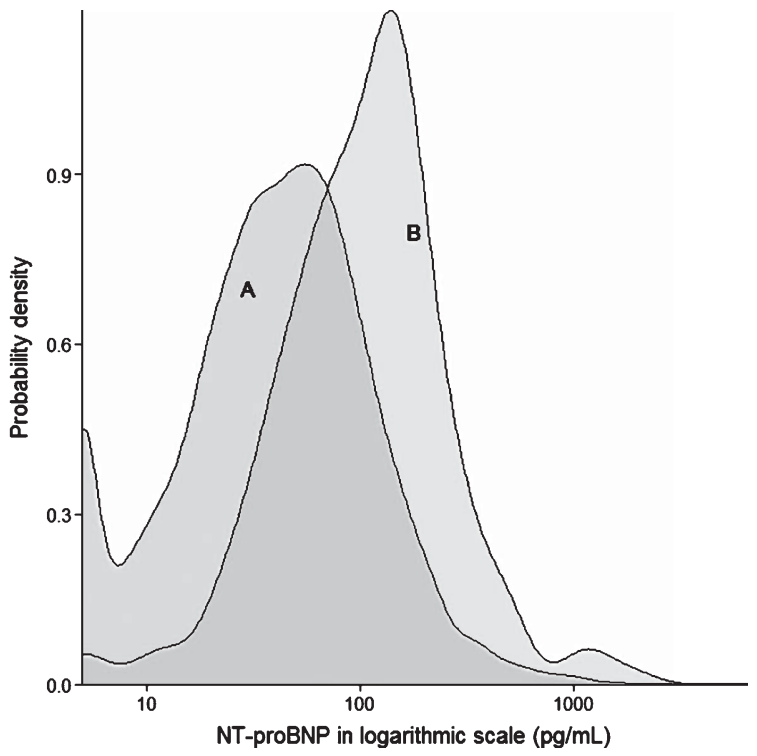

Fig. 1. Distribution of NT-proBNP (pg/mL) in logarithmic scale among subjects free of incident dementia (A) and with incident dementia (B). The peak at $5 \mathrm{pg} / \mathrm{mL}$ is due to the detection level of NT-proBNP.

subjects, the 33rd percentile of NT-proBNP was 27.2 $\mathrm{pg} / \mathrm{mL}$, the 66th percentile was $65.0 \mathrm{pg} / \mathrm{mL}$, and $72 \%$ of all dementia cases occurred among subjects with a baseline NT-proBNP above the 66th percentile.

In the entire study population, $\operatorname{logNT}$-proBNP was a significant predictor for future dementia after adjusting for other significant predictors. The hazard 
Table 2

The logNT-proBNP hazard ratio (HR) for incident dementia

\begin{tabular}{lccl}
\hline & HR $(\mathrm{CI} 95 \%)$ & $p$ & Adjusted for \\
\hline All & $1.32(1.17-1.56)$ & 0.001 & $\begin{array}{l}\text { Age, HDL, BMI, pIHD, } \\
\text { pDM*, Gender* }\end{array}$ \\
Men & $1.48(1.19-1.83)$ & $<0.001$ & Age, HDL, BMI, pIHD \\
Women & $1.17(0.90-1.52)$ & 0.245 & Age, BMI \\
\hline
\end{tabular}

Results are presented per 1 SD $\operatorname{logNT}$-proBNP from the Cox regression model among all participants and separately among men and women. HDL, high density lipoprotein; BMI, body mass index; pIHD, prevalent ischemic heart disease; pDM, prevalent diabetes. * Selected into model even if not statistically significant based on forward-stepping conditions $(p<0.1)$ in the regression model (see 'Methods').

ratio (HR) per 1SD logNT-proBNP was 1.32 (95\% CI 1.17-1.56, $p=0.001$ ) (Table 2). Correspondingly, among men, the HR for $1 \mathrm{SD} \operatorname{logNT}$-proBNP was 1.48 (95\%CI 1.19-1.83, $p<0.001$ ) (Table 2). Among women, $\operatorname{logNT}$-proBNP was not a significant predictor for dementia, but the direction of the association was the same as for men (HR 1.17, 95\%CI 0.90-1.52, $p=0.245$ ) (Table 2).

As there were no incident dementia cases among younger subjects ( $<40$ years), the reclassification value of NT-proBNP was evaluated primarily in subjects aged 40 years or more at baseline. The $\mathrm{C}$-index was 0.866 before and $0.865(p=0.494$ for difference) after adding NT-proBNP into the model derived using a forward-stepping regression model. The continuous net-reclassification improvement was $17.5 \%$ $(4.4-30.6 \%, p=0.009)$ and IDI $0.005(0.001-0.010$, $p=0.021)$. Among men aged 40 years or over, the $\mathrm{C}$ index was 0.856 before and 0.860 after addition of NT-proBNP into the model ( $p=0.286$ for difference). The continuous net-reclassification improvement was $25.7 \%(7.6-43.8 \%, p=0.005)$, and the IDI was 0.008 $(-0.002-0.018, p=0.101)$ (Table 3). This discrimination and reclassification analysis was not performed for women, since NT-proBNP was not significant in the Cox regression model.

Continuous NRI was no longer significant when evaluated in the entire study population (i.e., no age exclusion criteria), and there was a continuous net- reclassification improvement of $0.6 \%(-12.6-13.7 \%$, $p=0.932)$. However, IDI was significant 0.005 $(0.001-0.010, p=0.025)$. The reason for the fall in continuous NRI was the incorrectly upwards-reclassified non-cases, especially among younger subjects (data not shown).

To specify our analysis, we evaluated the association of NT-proBNP only with future AD based on drug reimbursement data from the National Social Insurance Institution's Drug Reimbursement Register: the HR for $1 \mathrm{SD} \operatorname{logNT}$-proBNP was 1.23 (95\%CI $1.01-1.49, p=0.040$ ) among the whole study population. The results among men and women showed the same trend but were not statistically significant: among men the HR was 1.19 (95\%CI 0.91-1.56, $p=0.207)$ and among women 1.08 (95\% CI $0.78-1.49, p=0.647$ ). The statistical power of this analysis was reduced by the smaller number of dementia cases $(n=149)$, but, based on our previous validation study, the diagnostic accuracy of the Drug Reimbursement Register is as high as $97 \%$ for AD [32]. No improvement was seen in $\mathrm{C}$-index, IDI, or cNRI for AD.

\section{DISCUSSION}

In earlier studies, NT-proBNP levels were shown to be elevated among demented patients [22, 23, 25], and the association between NT-proBNP and dementia risk was observed in two prospective studies [26, 27]. Our study is a large-scale prospective population-based study to evaluate this association, adjusting extensively for other risk factors in subjects without any specific predefined comorbidity (i.e., not limited to specific patient groups) and free of dementia at baseline. We observed that an increase in NT-proBNP was independently associated with the risk of dementia and that this association was especially strong among men. The confidence intervals for the HR estimates (95\% CIs) among women and men were widely overlapping but did not reach statistical significance among women, most likely due to insufficient statistical power to demonstrate this association.

Table 3

Discrimination and reclassification results with a $95 \%$ confidence interval after 10 -fold cross-validation

\begin{tabular}{lccc}
\hline & C-index & Continuous NRI & IDI \\
\hline All $>$ 40 years & 0.866 versus $0.865(p=0.494)$ & $17.5 \%(4.4-30.6 \%, p=0.009)$ & $0.005(0.001-0.010, p=0.021)$ \\
Men > 40 years & 0.856 versus $0.860(p=0.286)$ & $25.7 \%(7.6-43.8 \%, p=0.005)$ & $0.008(-0.002-0.018, p=0.101)$ \\
\hline
\end{tabular}

Models include all variables significant in the Cox regression model (Table 2) with and without logNT-proBNP among subjects aged 40 years or above at baseline. Analysis was not conducted separately for women, since logNT-proBNP was not significant among women. *Before versus after addition of $\operatorname{logNT}$-proBNP, $p$-value for difference. IDI, Integrated Discrimination Improvement; Continuous NRI, continuous net-reclassification improvement. 
Risk discrimination (IDI) and reclassification (continuous NRI) were improved with the addition of NT-proBNP on top of other significant risk factors. This effect was seen especially among subjects above 40 years of age and among men.

Limitations of our study are the lack of specific clinical evaluation of cognitive status at baseline and during follow-up. The exclusion criteria at baseline and incident dementia during the follow-up are based on register data. Nevertheless, we believe that the defined outcomes are valid, since in 1997-2010 all the anticholinesterase inhibitors (AChEIs) and memantine were under 'special reimbursement' and only neurology or geriatrics specialist was allowed to prepare an application for AChEIs or memantine. When AD was used as an endpoint, the results had the same tendency, but the statistical power was reduced by the smaller amount of dementia cases, and the association of NT-proBNP and AD was seen only among the study population as a whole (HR 1.23, 95\%CI 1.01-1.49, $p=0.040$ ). We know also from previous studies that the Finnish national register data on dementia are reliable in terms of high specificity, but the sensitivity is lower, i.e., we may be missing some dementia cases [32]. We cannot exclude the possibility that persons with both heart disease and dementia could be more likely to be brought to medical attention than other patients with dementia but no heart disease and normal NT-proBNP levels. This may have led to some overestimation of the effect of NT-proBNP. The fact that significantly elevated HR was also seen when analyzing AD only makes a substantial bias unlikely. Of the major risk factors for dementia, atrial fibrillation and milder cases of congestive heart failure may be underdiagnosed, since a substantial percentage of patients suffering from these conditions are treated in general/primary health care units and thus not included in the Hospital Discharge Register used in the present study. Due to this possible underestimation of the prevalence of these conditions, it is not certain whether the association between the risk of dementia and NT-proBNP is independent of these factors. Furthermore, we did not have the APOE status of participants, which is an independent risk factor for dementia [35]. In future studies, APOE status should be included, and it should be evaluated whether there is an interaction between APOE levels or APOE4 genotype and NT-proBNP-levels.

We speculate that some of this predictive value of NT-proBNP could be explained by cerebrovascular burden or silent atrial fibrillation and thereby also by increased risk of silent strokes, a condition which seems to be related to elevated NT-proBNP levels [36].
On the other hand, no association has been seen previously between the BNP level and silent vascular MRI changes in the 3.5 years of follow-up among middleaged people free of stroke [14].

Our findings indicate that NT-proBNP could be an eminent risk marker for dementia, especially among men. Yet its predictive value must be verified in another population-based study in which the baseline cognitive status is unequivocally characterized and the endpoint is confirmed clinically using a standardized methodology. If NT-proBNP proved to be a valid risk marker for dementia in later studies, it would provide an easily available laboratory parameter to more accurately detect patients at high risk for dementia. With more accurate long-term risk prediction, more precise monitoring of high risk subjects would become possible, leading to a more efficient detection of patients with clinical cognitive decline and at risk for dementia. Detection of high-risk patients years before the clinical signs of dementia become apparent could lead to preventive measures. This, however, requires a better understanding of the mechanisms by which NT-proBNP is associated with future dementia.

\section{ACKNOWLEDGMENTS}

This work has been was supported by the European Union Seventh Framework Programme (FP7/20072013) under Grant Agreement No. HEALTH-F2-2011278913 (BiomarCaRE). V. Salomaa was supported by the Finnish Foundation for Cardiovascular Research. J. Tynkkynen was supported by North Karelian Central Hospital in writing this paper as part of his doctoral thesis. None of the funders had any role in the design or conduct of the study; the collection, management, analysis or interpretation of the data; the preparation, review, or approval of the manuscript; or the decision to submit the manuscript for publication. J. Tynkkynen had full access to all the data in the study and takes responsibility for the integrity of the data and the accuracy of the data analysis.

Authors' disclosures available online (http://www.jalz.com/disclosures/view.php?id=2589).

\section{SUPPLEMENTARY MATERIAL}

The supplementary material is available in the electronic version of this article: http://dx.doi.org/ 10.3233/JAD-141809. 


\section{REFERENCES}

[1] Ganguli M, Fu B, Snitz BE, Hughes TF, Chang CC (2013) Mild cognitive impairment: Incidence and vascular risk factors in a population-based cohort. Neurology 80, 2112-2120.

[2] Crane PK, Walker R, Hubbard RA, Li G, Nathan DM, Zheng H, Haneuse S, Craft S, Montine TJ, Kahn SE, McCormick W, McCurry SM, Bowen JD, Larson EB (2013) Glucose levels and risk of dementia. N Engl J Med 369, 540-548.

[3] Ronnemaa E, Zethelius B, Lannfelt L, Kilander L (2011) Vascular risk factors and dementia: 40-year follow-up of a population-based cohort. Dement Geriatr Cogn Disord 31, 460-466.

[4] Ruitenberg A, Skoog I, Ott A, Aevarsson O, Witteman JC, Lernfelt B, van Harskamp F, Hofman A, Breteler MM (2001) Blood pressure and risk of dementia: Results from the Rotterdam study and the Gothenburg H-70 Study. Dement Geriatr Cogn Disord 12, 33-39.

[5] Alonso A, Mosley TH Jr, Gottesman RF, Catellier D, Sharrett AR, Coresh J (2009) Risk of dementia hospitalisation associated with cardiovascular risk factors in midlife and older age: The Atherosclerosis Risk in Communities (ARIC) study. J Neurol Neurosurg Psychiatry 80, 1194-1201.

[6] Rusanen M, Kivipelto M, Quesenberry CP, Jr, Zhou J, Whitmer RA (2011) Heavy smoking in midlife and long-term risk of Alzheimer disease and vascular dementia. Arch Intern Med 171, 333-339.

[7] Kivipelto M, Helkala EL, Laakso MP, Hanninen T, Hallikainen M, Alhainen K, Soininen H, Tuomilehto J, Nissinen A (2001) Midlife vascular risk factors and Alzheimer's disease in later life: Longitudinal, population based study. BMJ 322, 1447-1451.

[8] Kester MI, van der Flier WM, Mandic G, Blankenstein MA, Scheltens P, Muller M (2010) Joint effect of hypertension and APOE genotype on CSF biomarkers for Alzheimer's disease. J Alzheimers Dis 20, 1083-1090.

[9] Mielke MM, Leoutsakos JM, Tschanz JT, Green RC, Tripodis Y, Corcoran CD, Norton MC, Lyketsos CG (2011) Interaction between vascular factors and the APOE epsilon4 allele in predicting rate of progression in Alzheimer's disease. $J$ Alzheimers Dis 26, 127-134.

[10] Kaffashian S, Dugravot A, Elbaz A, Shipley MJ, Sabia S, Kivimaki M, Singh-Manoux A (2013) Predicting cognitive decline: A dementia risk score vs the Framingham vascular risk scores. Neurology 80, 1300-1306.

[11] Kivipelto M, Ngandu T, Laatikainen T, Winblad B, Soininen H, Tuomilehto J (2006) Risk score for the prediction of dementia risk in 20 years among middle aged people: A longitudinal, population-based study. Lancet Neurol 5, 735-741.

[12] Exalto LG, Quesenberry CP, Barnes D, Kivipelto M, Biessels GJ, Whitmer RA (2014) Midlife risk score for the prediction of dementia four decades later. Alzheimers Dement 10, 562570 .

[13] Blankenberg S, Zeller T, Saarela O, Havulinna AS, Kee F, Tunstall-Pedoe H, Kuulasmaa K, Yarnell J, Schnabel RB, Wild PS, Munzel TF, Lackner KJ, Tiret L, Evans A, Salomaa V, MORGAM Project (2010) Contribution of 30 biomarkers to 10-year cardiovascular risk estimation in 2 population cohorts: The MONICA, risk, genetics, archiving, and monograph (MORGAM) biomarker project. Circulation 121, 2388-2397.

[14] Pikula A, Beiser AS, DeCarli C, Himali JJ, Debette S, Au R, Selhub J, Toffler GH, Wang TJ, Meigs JB, Kelly-Hayes M, Kase CS, Wolf PA, Vasan RS, Seshadri S (2012) Multiple biomarkers and risk of clinical and subclinical vascular brain injury: The Framingham Offspring Study. Circulation 125, 2100-2107.

[15] Wang TJ, Larson MG, Levy D, Benjamin EJ, Leip EP, Omland T, Wolf PA, Vasan RS (2004) Plasma natriuretic peptide levels and the risk of cardiovascular events and death. $N$ Engl J Med 350, 655-663.

[16] Patton KK, Ellinor PT, Heckbert SR, Christenson RH, DeFilippi C, Gottdiener JS, Kronmal RA (2009) N-terminal pro-B-type natriuretic peptide is a major predictor of the development of atrial fibrillation: The Cardiovascular Health Study. Circulation 120, 1768-1774.

[17] Smith JG, Newton-Cheh C, Almgren P, Struck J, Morgenthaler NG, Bergmann A, Platonov PG, Hedblad B, Engstrom G, Wang TJ, Melander O (2010) Assessment of conventional cardiovascular risk factors and multiple biomarkers for the prediction of incident heart failure and atrial fibrillation. $J A m$ Coll Cardiol 56, 1712-1719.

[18] Ledwidge M, Gallagher J, Conlon C, Tallon E, O'Connell E, Dawkins I, Watson C, O'Hanlon R, Bermingham M, Patle A, Badabhagni MR, Murtagh G, Voon V, Tilson L, Barry M, McDonald L, Maurer B, McDonald K (2013) Natriuretic peptide-based screening and collaborative care for heart failure: The STOP-HF randomized trial. JAMA 310, 66-74.

[19] McMurray JJ, Adamopoulos S, Anker SD, Auricchio A, Bohm M, Dickstein K, Falk V, Filippatos G, Fonseca C, Gomez-Sanchez MA, Jaarsma T, Kober L, Lip GY, Maggioni AP, Parkhomenko A, Pieske BM, Popescu BA, Ronnevik PK, Rutten FH, Schwitter J, Seferovic P, Stepinska J, Trindade PT, Voors AA, Zannad F, Zeiher A, Task Force for the Diagnosis and Treatment of Acute and Chronic Heart Failure 2012 of the European Society of Cardiology, Bax JJ, Baumgartner H, Ceconi C, Dean V, Deaton C, Fagard R, Funck-Brentano C, Hasdai D, Hoes A, Kirchhof P, Knuuti J, Kolh P, McDonagh T, Moulin C, Popescu BA, Reiner Z, Sechtem U, Sirnes PA, Tendera M, Torbicki A, Vahanian A, Windecker S, McDonagh T, Sechtem U, Bonet LA, Avraamides P, Ben Lamin HA, Brignole M, Coca A, Cowburn P, Dargie H, Elliott P, Flachskampf FA, Guida GF, Hardman S, Iung B, Merkely B, Mueller C, Nanas JN, Nielsen OW, Orn S, Parissis JT, Ponikowski P, ESC Committee for Practice Guidelines (2012) ESC guidelines for the diagnosis and treatment of acute and chronic heart failure 2012: The Task Force for the Diagnosis and Treatment of Acute and Chronic Heart Failure 2012 of the European Society of Cardiology. Developed in collaboration with the Heart Failure Association (HFA) of the ESC. Eur J Heart Fail 14, 803-869.

[20] Olsen MH, Hansen TW, Christensen MK, Gustafsson F, Rasmussen S, Wachtell K, Ibsen H, Torp-Pedersen C, Hildebrandt PR (2007) N-terminal pro-brain natriuretic peptide, but not high sensitivity $\mathrm{C}$-reactive protein, improves cardiovascular risk prediction in the general population. Eur Heart $J \mathbf{2 8}$, 1374-1381.

[21] Reitz C, Brickman AM, Luchsinger JA, Wu WE, Small SA, Tang MX (2007) Frequency of subclinical heart disease in elderly persons with dementia. Am J Geriatr Cardiol 16, 183188.

[22] Gunstad J, Poppas A, Smeal S, Paul RH, Tate DF, Jefferson AL, Forman DE, Cohen RA (2006) Relation of brain natriuretic peptide levels to cognitive dysfunction in adults $>55$ years of age with cardiovascular disease. Am J Cardiol 98, 538-540.

[23] Feola M, Rosso GL, Peano M, Agostini M, Aspromonte N, Carena G, Salvatico L, Valle R (2007) Correlation between cognitive impairment and prognostic parameters in patients with congestive heart failure. Arch Med Res 38, 234-239. 
[24] Marksteiner J, Imarhiagbe D, Defrancesco M, Deisenhammer EA, Kemmler G, Humpel C (2014) Analysis of 27 vascular-related proteins reveals that NT-proBNP is a potential biomarker for Alzheimer's disease and mild cognitive impairment: A pilot-study. Exp Gerontol 50, 114-121.

[25] Naito J, Naka Y, Watanabe H (2009) Clinical impression of brain natriuretic peptide levels in demented patients without cardiovascular disease. Geriatr Gerontol Int 9, 242-245.

[26] Kerola T, Nieminen T, Hartikainen S, Sulkava R, Vuolteenaho O, Kettunen R (2010) B-type natriuretic peptide as a predictor of declining cognitive function and dementia-a cohort study of an elderly general population with a 5-year follow-up. Ann Med 42, 207-215.

[27] Feinkohl I, Keller M, Robertson CM, Morling JR, Williamson RM, Nee LD, McLachlan S, Sattar N, Welsh P, Reynolds RM, Russ TC, Deary IJ, Strachan MW, Price JF, Edinburgh Type 2 Diabetes Study (ET2DS) Investigators (2013) Clinical and subclinical macrovascular disease as predictors of cognitive decline in older patients with type 2 diabetes: The Edinburgh Type 2 Diabetes Study. Diabetes Care 36, 2779-2786.

[28] Hu WT, Holtzman DM, Fagan AM, Shaw LM, Perrin R, Arnold SE, Grossman M, Xiong C, Craig-Schapiro R, Clark CM, Pickering E, Kuhn M, Chen Y, Van Deerlin VM, McCluskey L, Elman L, Karlawish J, Chen-Plotkin A, Hurtig HI, Siderowf A, Swenson F, Lee VM, Morris JC, Trojanowski JQ, Soares H, Alzheimer's Disease Neuroimaging, Initiative (2012) Plasma multianalyte profiling in mild cognitive impairment and Alzheimer disease. Neurology 79, 897-905.

[29] (1988) The World Health Organization MONICA Project (monitoring trends and determinants in cardiovascular dis- ease): A major international collaboration. WHO MONICA Project Principal Investigators. J Clin Epidemiol 41, 105-114.

[30] Vartiainen E, Laatikainen T, Peltonen M, Juolevi A, Mannisto S, Sundvall J, Jousilahti P, Salomaa V, Valsta L, Puska $\mathrm{P}$ (2010) Thirty-five-year trends in cardiovascular risk factors in Finland. Int J Epidemiol 39, 504-518.

[31] Pajak A, Kuulasmaa K, Tuomilehto J, Ruokokoski E (1988) Geographical variation in the major risk factors of coronary heart disease in men and women aged 35-64 years. The WHO MONICA Project. World Health Stat Q 41, 115-140.

[32] Solomon A, Ngandu T, Soininen H, Hallikainen MM, Kivipelto M, Laatikainen T (2014) Validity of dementia and Alzheimer disease diagnoses in Finnish national registers. Alzheimers Dement 10, 303-309.

[33] Vest RS, Pike CJ (2013) Gender, sex steroid hormones, and Alzheimer's disease. Horm Behav 63, 301-307.

[34] Vina J, Lloret A (2010) Why women have more Alzheimer's disease than men: Gender and mitochondrial toxicity of amyloid-beta peptide. J Alzheimers Dis 20(Suppl 2), S527S533.

[35] Gupta VB, Laws SM, Villemagne VL, Ames D, Bush AI, Ellis KA, Lui JK, Masters C, Rowe CC, Szoeke C, Taddei K, Martins RN, Research AIBL, Group (2011) Plasma apolipoprotein E and Alzheimer disease risk: The AIBL study of aging. Neurology 76, 1091-1098.

[36] Knecht S, Oelschlager C, Duning T, Lohmann H, Albers J, Stehling C, Heindel W, Breithardt G, Berger K, Ringelstein EB, Kirchhof P, Wersching H (2008) Atrial fibrillation in stroke-free patients is associated with memory impairment and hippocampal atrophy. Eur Heart J 29, 2125-2132. 